\section{Metal constituents of e-waste black powder and its potential utilization}

\author{
Pawan Kumar Bharti ${ }^{1, *}$, R. K. Singh ${ }^{1}$, \\ Raju Joshi ${ }^{2}$, Shambhu Thakur ${ }^{3}$ and A. K. Tyagi ${ }^{1}$ \\ ${ }^{1} \mathrm{R} \& \mathrm{D}$ Division, \\ ${ }^{2}$ Analytical Science Division, and \\ ${ }^{3}$ Metal and Minerals Division, Shriram Institute for Industrial \\ Research, 19, University Road, Delhi 110 007, India
}

Electronic waste (e-waste) generation is one of the major emerging problems of the modern era and requires consideration at the global, national and local levels. Moradabad, Uttar Pradesh, is one of the biggest hubs of e-waste recycling in India, where almost $50 \%$ of printed circuit boards (PCBs) waste of the country is being handled with the engagement of more than 50,000 people.

Black ash of PCBs is overtly dumped after carrying out recycling processes in the vicinity. The dumping is affecting the aquatic and terrestrial ecosystems of the vicinity due to this black powder ash. Analysis of ewaste black ash sample was carried out for metal content using ICP-OES. A significant amount of lead, copper, barium, tin, aluminium, silica, etc. was found in the e-waste black powder, which indicates the potential utilization of e-waste black powder in many applications. Hence there is an immediate need of an environment-friendly technology for e-waste recycling and to safeguard the environment.

Keywords: Black powder, electronic-waste recycling, environmental pollution, metal analysis.

ElECTRONIC waste (e-waste) is a term that describes unwanted, obsolete and useless, discarded electrical or electronic devices. It may contain unsafe components and constituents like cadmium, lead, beryllium or brominated substances. Unscientific, crude and informal recycling of e-waste involves threat to worker's health and also leads to emission of hazardous materials such as toxic metals ${ }^{1}$. Informal recycling and processing of e-waste in developing countries like India can lead to emission of risky pollutants, which can have undesirable impacts on environmental components and human health.

E-waste includes superfluous and discarded computers, office equipment, amusement devices, mobile phones, gadgets, refrigerators, TVs, etc. It also includes used electronics, which is intended for reuse, recycling, salvage, resale or disposal ${ }^{1,2}$. Some of the electronic waste components can be used to recover the valuable fragments like steel, copper, plastic, etc. Several components are dumped rather than recycled. Cathode ray tubes from $\mathrm{TV}$ s are considered one of the hardest items to recycle ${ }^{2,3}$.

\footnotetext{
*For correspondence. (e-mail: gurupawanbharti@rediffmail.com)
}

In developing countries, e-waste is being generated continuously at a rapid rate. The e-waste generation and informal recycling need to be addressed in India to deal with the dangerous impacts of noxious substances present in it on the environment and human beings ${ }^{4}$. The current recycling practices of e-waste in India need critical consideration and hence there is an urgent requirement of an environment-friendly and scientific technology for e-waste recycling and management. Recyclers and dismantlers are explicitly dumping residual ash of e-waste generated from crude recycling processes. Apart from human exposure, the black ash powder is also affecting aquatic and terrestrial ecosystems of the region ${ }^{5}$. Hence, there is a need to formulate an appropriate strategy to reduce e-waste pollution.

Since the last decade, Moradabad district in Uttar Pradesh (UP), India has been hub for recycling of e-waste in a crude and nonscientific manner. It generates approximately 9 tonnes of risky waste daily; and over 50,000 people are engaged in this work directly or indirectly. Most of the dismantling and recycling done here is illegal. According to a report of the Centre for Science and Environment $(\mathrm{CSE})^{5}$ on e-waste recycling in Moradabad city, the condition is distressing. The dismantlers and recyclers face severe health issues, and the recycling and processing industry poses a serious threat to the environment $^{6}$. Thus there is a need to monitor e-waste recycling/process-related activities in Moradabad region. Karula, Nawabpura, Daswaghat, Jama Masjid, Gulab Bagh and Rehmat Nagar and Bhojpur are the major e-waste handling centres.

Black powder ash is generated during the crude recycling process of e-waste. Studies have shown that the water and soil of the Moradabad region contain objectionable quantities of several heavy metals, which are hazardous to the environment and can cause severe health problems, including cancer ${ }^{5,7,8}$. High concentration of arsenic and mercury can lead to poisoning. Mercury reaches the food chain through bio-accumulation and biomagnification in aquatic life forms. It is a well known neurotoxin and interferes with the brain functioning and ultimately the entire nervous system ${ }^{6,9}$. High concentration of nickel, cobalt and zinc lead to sub-clinical issues which may not be monitored on the basis of symptoms, but persist ${ }^{3,6,10}$.

E-waste black powder sample was collected in a polythene bag from the banks of Ramganga river at Moradabad (Figure 1).

After collection of the sample (Figure 2), it was prepared for general parameters and metal analysis according to the specific requirement of each parameter.

Ground and homogenous sample was taken in a ceramic crucible and heated in oven at $105^{\circ} \mathrm{C}$ for $3 \mathrm{~h}$ to remove the moisture content. The moisture content was calculated by weight loss of the sample taken. 

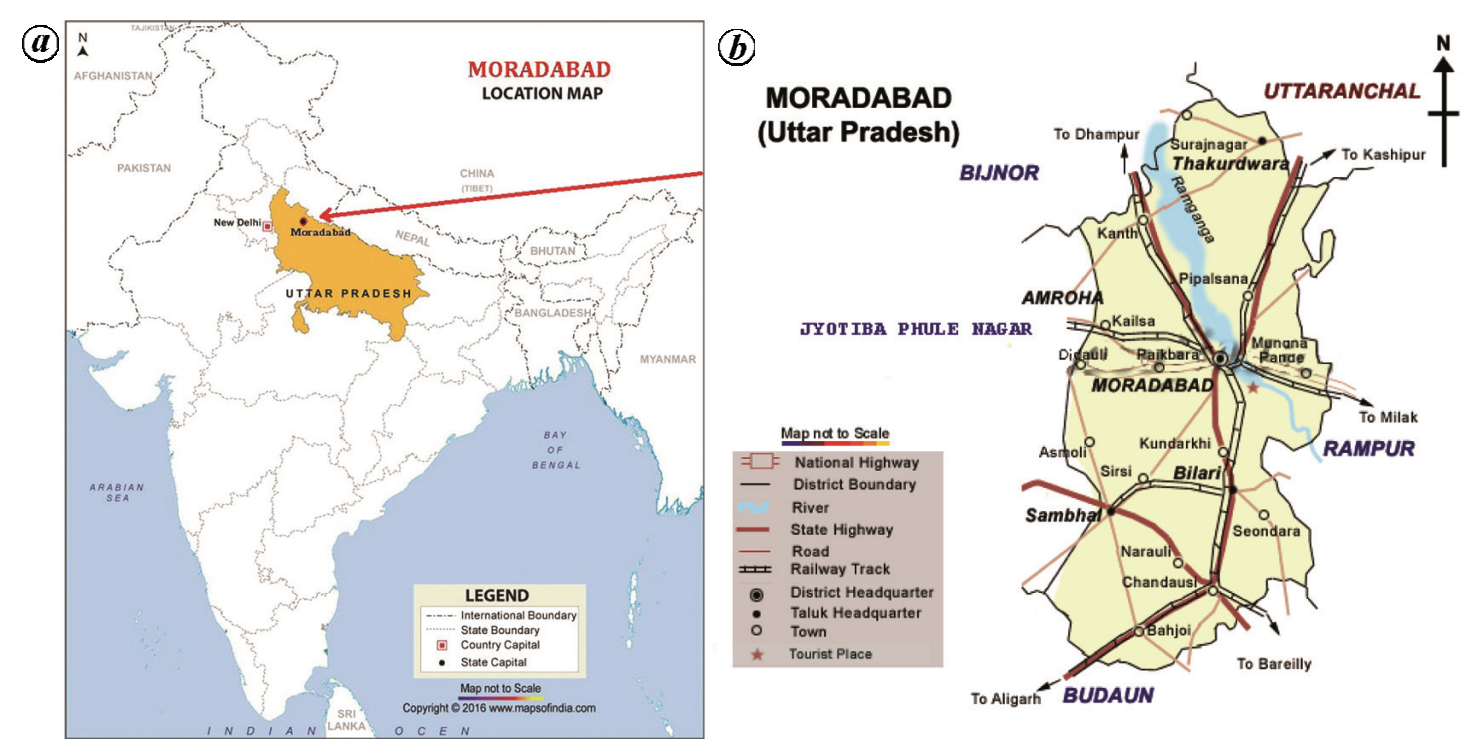

Figure $1 \boldsymbol{a}, \boldsymbol{b}$. Location map of the study area (Moradabad).

Table 1. Weight loss at different temperature zone

\begin{tabular}{lccc}
\hline & \multicolumn{3}{c}{ Weight loss $(\%)$} \\
\cline { 2 - 4 } Sample no. & $105^{\circ} \mathrm{C}$ & $400^{\circ} \mathrm{C}$ & $600^{\circ} \mathrm{C}$ \\
\hline 1 & 17.59 & 30.26 & 40.84 \\
2 & 18.20 & 30.60 & 42.58 \\
Average & 17.89 & 30.43 & 41.71 \\
\hline
\end{tabular}

The sample was taken in a ceramic crucible and heated in an oven at $400^{\circ} \mathrm{C}$ for $6 \mathrm{~h}$ to remove the volatile content. The organic part was calculated using weight loss of the sample. The dried sample was prepared by fusion for the analysis of major metals like $\mathrm{Pb}, \mathrm{Ba}, \mathrm{B}, \mathrm{Sb}$, $\mathrm{Sn}, \mathrm{Si}, \mathrm{Cu}, \mathrm{Fe}$, etc. in the sample.

The sample was taken in a ceramic crucible and heated in an oven at $600^{\circ} \mathrm{C}$ for $6 \mathrm{~h}$ to remove the complete stable organic content and a few metals like lead in black powder. This load was calculated by total weight loss of the sample taken. The dried sample was fused for the analysis of all metal constituents and digested for analysis of tungsten content.

One gram of fusion mixture (a mixture of sodium carbonate and potassium nitrate) was taken in platinum crucible to fuse the sample for analysis of various metals. Next $1 \mathrm{~g}$ of dried ash sample was added followed by $0.5 \mathrm{~g}$ of fusion mixture. The contents were heated in a furnace at $800-900^{\circ} \mathrm{C}$ for half an hour. After $10 \mathrm{~min}$, mix the content of crucible, if melting appears and put again in furnace. After $30 \mathrm{~min}$, keep the crucible for cooling and transfer the platinum crucible in $100-150 \mathrm{ml}$ of $\mathrm{HCl}$ solution $(50 \%)$ and boil for further $30 \mathrm{~min}$. After cooling, its volume was made up to $100 \mathrm{ml}$ using ultra quality Millipore water.

After drying $600^{\circ} \mathrm{C}$ for $6 \mathrm{~h}, 1 \mathrm{~g}$ of sample was taken in a Teflon crucible for the analysis of tungsten. Next, 1$2 \mathrm{ml}$ of hydrofluoric acid (HF) and $2-3 \mathrm{ml}$ of nitric acid $\left(\mathrm{HNO}_{3}\right)$ were added and the sample was heated on a hot plate at $150^{\circ} \mathrm{C}$ for drying. On cooling, it was made up to $50 \mathrm{ml}$ using ultra quality Millipore water.

After hot plate digestion and fusion of the sample, dilutions were prepared using ultra quality Millipore water before analysis using ICP-OES, according to the elemental requirement.

After dilution, metal analysis was carried out using ICP-OES. Parallel blanks and appropriate standards were also prepared.

To minimize influence of various analytical errors on the results of different variables, a few statistical tools correlations were performed between the individual variables using MS-Excel. Dilution factor was also calculated to obtain the true value of elements in the sample.

The residual black powder samplehad moisture content of $18 \%$, which indicates residual water content used in post recycling activities of e-waste. Table 1 gives the weight loss values $(\%)$ of the sample at different temperatures. Other volatile materials constituted $12 \%$ of the sample in addition to moisture content, while total organic material was $11-12 \%$ of total weight. Metal constituents in black ash powder of e-waste were analysed (Table 2).

Table 3 gives the major metal constituents of dry ash of the sample. Copper content in the sample was found to be $21.45 \%$, followed by calcium $(15.17 \%)$ and silica $(2.11 \%)$. Iron, aluminium, lead, tin, zinc and antimony were also found in significant amounts. Copper was detected maximum 214,495 ppm in dry sample using the digestion method and calcium was found to be $151,688 \mathrm{ppm}$ using the fusion method. Other metals like tin (5205 ppm), iron (7078 ppm), aluminium (7078 ppm), zinc $(5015 \mathrm{ppm})$, antimony $(1713 \mathrm{ppm})$, barium (493 ppm) and boron (173 ppm) were found in significant amounts, which can be utilized in different applications or making a suitable useful product from embankment blocks, pavement bricks, radiation shielding materials, 

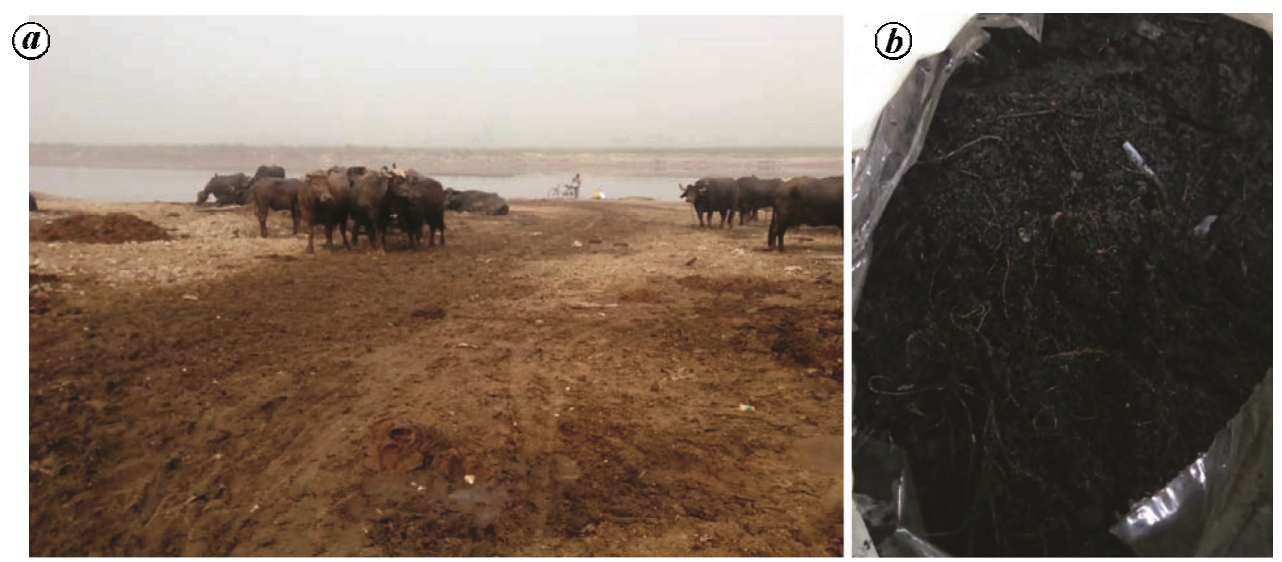

Figure 2. Dumping site (a) and black powder sample collected (b).

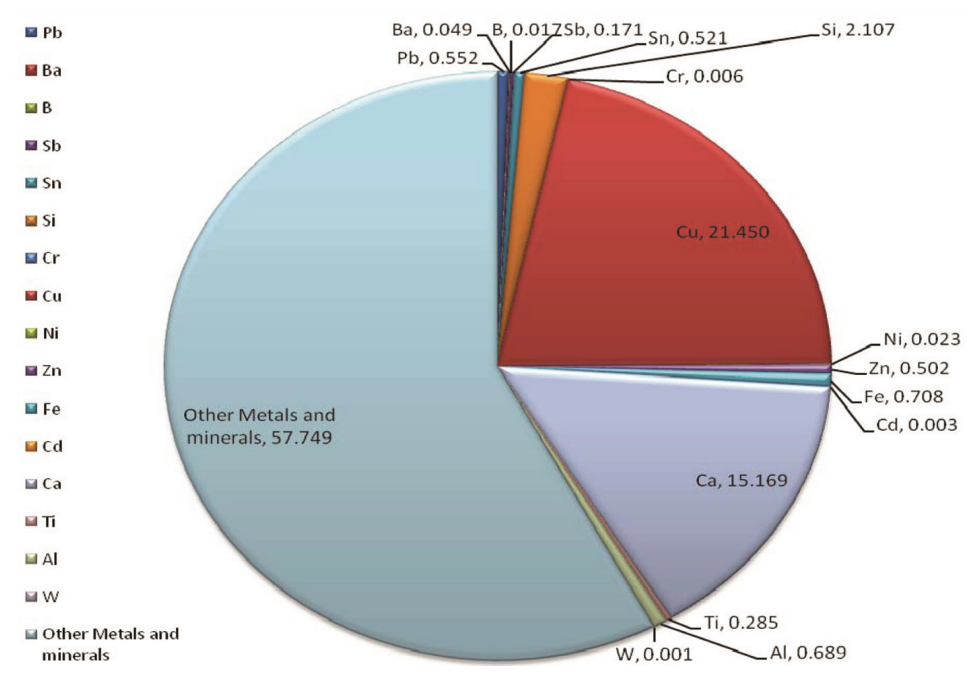

Figure 3. Metal component (\%) in e-waste black powder.

Table 2. Metal concentrations in e-waste black powder

\begin{tabular}{lccc}
\hline Metal & Dried @ ${ }^{\circ} \mathrm{C}$ & Digestion/fusion & Value $(\mathrm{ppm})$ \\
\hline $\mathrm{Pb}$ & 400 & Fusion & 5516.1 \\
$\mathrm{Ba}$ & 600 & Fusion & 493.2 \\
$\mathrm{~B}$ & 600 & Digestion & 173.0 \\
$\mathrm{Sb}$ & 400 & Digestion & 1713.4 \\
$\mathrm{Sn}$ & 600 & Fusion & 5205.2 \\
$\mathrm{Si}$ & 400 & Fusion & 21070.3 \\
$\mathrm{Cr}$ & 600 & Fusion & 62.3 \\
$\mathrm{Cu}$ & 400 & Digestion & $214,495.1$ \\
$\mathrm{Ni}$ & 600 & Digestion & 228.6 \\
$\mathrm{Zn}$ & 400 & Digestion & 5015.9 \\
$\mathrm{Fe}$ & 600 & Fusion & 7078.4 \\
$\mathrm{Cd}$ & 400 & Digestion & 26.5 \\
$\mathrm{Ca}$ & 600 & Fusion & 151,688 \\
$\mathrm{Ti}$ & 600 & Digestion & 2845.7 \\
$\mathrm{Al}$ & 600 & Fusion & 6893.3 \\
$\mathrm{~W}$ & 600 & Fusion & 8.3 \\
\hline
\end{tabular}

reinforcement in mortar, etc. and extracting copper metal and silicon from e-waste black powder.

Some metals cause environmental pollution when disposed near a river bank or openly dumped into fields.
Table 3. Major metal content (\%) in e-waste black powder

\begin{tabular}{lccc}
\hline Metal & Percentage & Metal & Percentage \\
\hline $\mathrm{Cu}$ & 21.45 & $\mathrm{Sn}$ & 0.52 \\
$\mathrm{Ca}$ & 15.17 & $\mathrm{Zn}$ & 0.50 \\
$\mathrm{Si}$ & 2.11 & $\mathrm{Sb}$ & 0.17 \\
$\mathrm{Fe}$ & 0.71 & $\mathrm{Ba}$ & 0.05 \\
$\mathrm{Al}$ & 0.69 & $\mathrm{~B}$ & 0.02 \\
$\mathrm{~Pb}$ & 0.55 & & \\
\hline
\end{tabular}

Water and soil quality may be heavily influenced by the disposal of e-waste black powder due to the occurrence of toxic heavy metals. Lead (5516 ppm), cadmium (62.3 ppm) and chromium (26.5 ppm) were also detected in the e-waste black powder sample, which can be hazardous to the environment ${ }^{5}$.

The metal constituents of e-waste black powder can be used in many applications. A few metals are having nutritional values for plants, i.e. zinc, nickel, boron, iron and copper, but this black powder cannot be applied directly to plant roots, without eliminating hazardous elements. Metals such as lead, barium, bismuth, tin, 
antimony and tungsten have radiation shielding properties and can be utilized in making radiation shielding walls, blocks or panels in various applications.

Copper was found to be $21 \%$ of total dry weight of black powder. The black slag containing copper can be utilized in the manufacture of cement and preparation of mortar and concrete. It can be mixed with limestone, dust, etc. and can be used as replacement and partial substitute of fine and coarse aggregates. Construction of road embankment using copper slag alone is not feasible as copper slag is a cohesion-less material. One of the options is to mix the slag with local cohesive soil. Copper slag can be mixed with black soils in different proportions and soil properties can be modified using copper for selected plant species in selected types of soil ${ }^{11-13}$. Copper can be extracted from the e-waste black powder using appropriate techniques, viz. industrial route ${ }^{14}$, or by sulphation roasting and water leaching method ${ }^{15}$. Apart from valuable metals such as $\mathrm{Au}, \mathrm{Pd}$ and $\mathrm{Ag}$, some base metals such as $\mathrm{Cu}, \mathrm{Pb}, \mathrm{Ni}$ and $\mathrm{Zn}$ can also be extracted from e-waste or black powder due to their economic importance.

Calcium can be utilized in various applications like steel-making and in drain cleaner formulations. It can be used to eradicate nitrogen from high-purity argon gas and can act as a recipient for nitrogen and oxygen gases. It also acts as a reducing agent in the production of zirconium, uranium, chromium and thorium. Calcium can be used to store hydrogen gas, as it reacts with hydrogen to form a solid calcium hydride which can further easily liberate the hydrogen gas ${ }^{16}$.

Silica can be used for making fused quartz, aerogels, silica gel and fumed silica. It can also be used in basic structural materials, micro-electronics and as components in the food, dietry supplements and pharmaceutical sector $^{17}$. Silicon was found to be dominant among all the metal constituents in e-waste black powder sample and can be a good source of raw material for various applications.

E-waste is being generated continuously at a rapid rate in developing countries, including India. The e-waste disposal and recycling problem needs to be dealt with scientifically to reduce the detrimental effects of the toxic substances present in the black powder of processed e-waste. The unscientific and crude methods of disposal of e-waste have negative impacts on human health and the environment ${ }^{18,19}$. Thus e-waste processing and recycling should be performed in a scientific and sustainable manner. Further, it is suggested that the UP Government must implement suitable integrated strategies to combat against e-waste-related pollution. The major constituents of black powder can be used for making useful products such as pavement blocks, embankment bricks or radiation-shielding concrete panels in Moradabad. Also, copper can be extracted from this black powder using appropriate advance techniques ${ }^{14,15}$.
1. Perkins, D. N., Brune Drisse, M. N., Nxele, T. and Sly, P. D., Ewaste: a global hazard. Ann. Global Health, 2014, 80(4), 286-295.

2. https://en.wikipedia.org/wiki/electronic waste (accessed on 8 February 2018)

3. Song, Q. and Li, J., A systematic review of the human body burden of e-waste exposure in China. Environ. Int., 2014, 68, 82-93.

4. Park, J. K., Hoerning, L., Watry, S., Burgett, T. and Matthias, S., Effects of electronic waste on developing countries. Adv. Recycl. Waste Manage., 2017, 2, 128; doi:10.4172/2475-7675.1000128.

5. CSE, Recommendations to address the issues of informal sector involved in e-waste handling: Moradabad, Uttar Pradesh. Centre for Science and Environment, 2015, pp. 1-16.

6. Garlapati, V. K., E-waste in India and developed countries: management, recycling, business and biotechnological initiatives. Renew. Sustain. Energy Rev., 2016, 54, 874-881.

7. Kumar, A., Holuszko, M. and Espinosa, D. C. R., E-waste: an overview on generation, collection, legislation and recycling practices. Resour. Conserv. Recycl., 2017, 122, 32-42.

8. Baldé, C. P., Forti, V., Gray, V., Kuehr, R. and Stegmann, P., The global e-waste monitor - 2017, United Nations University, International Telecommunication Union and International Solid Waste Association, Bonn/Geneva/Vienna, 2017, p. 116.

9. Sthiannopkao, S. and Wong, M. H., Handling e-waste in developed and developing countries: Initiatives, practices, and consequences. Sci. Total Environ., 2013, 463, 1147-1153.

10. Zhao, G., Wang, Z., Zhou, H. and Zhao, Q., Burdens of PBBs, PBDEs, and PCBs in tissues of the cancer patients in the e-waste disassembly sites in Zhejiang, China. Sci. Total Environ., 2009, 407, 4831-4837.

11. Tandel, Y. K. and Patel, J. B., Review of utilisation of copper slag in highway construction. Aust. Geomech., 2009, 44(3), 71-80.

12. Terazono, A., Oguchi, M., Yoshida, A., Medina, R. P. and Ballesteros, F. C., Metal recovery and environmental impact by informal e-waste recycling sites in Philippines. In Sustainability through Innovation Product Life Cycle Design (eds Matsumoto, M. et al.), Springer Link, 2016, pp. 197-213.

13. Zhang, W. H., Wu, Y. X. and Simonnot, M. O., Soil contamination due to e-waste disposal and recycling activities: a review with special focus on China. Pedos, 2012, 22, 434-455.

14. Abdul, K., Rhamdhani, M. A., Brooks, G. and Masood, S., Metal extraction processes for electronic waste and existing industrial routes: a review and Australian perspective. Resources, 2014, 3, $152-179$.

15. Dimitrijevic, M. D., Urosevic, D. M., Jankovic, Z. D. and Milic, S. M., Recovery of copper from smelting slag by sulphation roasting and water leaching. Physicochem. Probl. Miner. Process., 2016, 52(1), 409-421.

16. Rumack, BH POISINDEX (R). Information System Micromedex, Inc., Englewood, CO (eds Hall, A. H. and Rumack, B. H.), CCIS, 2010, vol. 143.

17. Flörke, O. W. et al., In Ullmann's Encyclopedia of Industrial Chemistry, Wiley-VCH, Weinheim, 2008; doi:10.1002/ 14356007.a23_583.pub3.

18. An, D., Yang, Y., Chai, X., Xi, B. and Dong, L., Mitigating pollution of hazardous materials from WEEE of China: portfolio selection for a sustainable future based on multi-criteria decision making. Resour. Conserv. Recyc., 2015, 105, 198-210.

19. Bharti, P. K., Singh, R. K. and Tyagi, A. K., Site reclamation and utilization of e-waste black powder in making concrete blocks for pavements. Octa J. Environ. Res., 2018, 6(2), 94-100.

ACKNOWLEDGEMENTS. We thank the management of Shriram Institute for Industrial Research, Delhi for providing the necessary facilities to conduct this study. We acknowledge help from the preliminary work of Centre for Science and Environment (CSE), New Delhi, on the same subject.

Received 3 August 2018; revised accepted 4 October 2018

doi: $10.18520 / \mathrm{cs} / \mathrm{v} 116 / \mathrm{i} 1 / 104-107$ 